Research Article

\title{
Studies of Two-Phase Flow at a Chute Aerator with Experiments and CFD Modelling
}

\author{
Penghua Teng, ${ }^{1}$ James Yang, ${ }^{1,2}$ and Michael Pfister ${ }^{3,4}$ \\ ${ }^{1}$ Hydraulic Engineering, Royal Institute of Technology (KTH), 10044 Stockholm, Sweden \\ ${ }^{2}$ Fluid Mechanics, Vattenfall R\&D, 81470 Älvkarleby, Sweden \\ ${ }^{3}$ Civil Engineering, Haute Ecole d'Ingénierie et d'Architecture de Fribourg (HEIA-FR), 1705 Fribourg, Switzerland \\ ${ }^{4}$ Laboratory of Hydraulic Constructions, Ecole Polytechnique Fédérale de Lausanne (EPFL), 1015 Lausanne, Switzerland
}

Correspondence should be addressed to Penghua Teng; teng.penghua@byv.kth.se

Received 17 May 2016; Accepted 25 July 2016

Academic Editor: ShengKai Yu

Copyright (c) 2016 Penghua Teng et al. This is an open access article distributed under the Creative Commons Attribution License, which permits unrestricted use, distribution, and reproduction in any medium, provided the original work is properly cited.

\begin{abstract}
The chute aerator of a spillway is a structure in such a sense that air is, in the intense emulsification, entrained into the highvelocity water flow. Correctly predicting the air entrainment and two-phase flow pattern at the aerator would contribute to reliable spillway operation. Based on experimental data, 2D numerical simulations are preformed to predict streamwise air concentrations in the aerated flow, in which a two-fluid model is used. Depending on the air bubble size, relatively good agreement is seen with the experiments in the air cavity zone. The simulations give rise to higher air concentration downstream of the cavity, which is presumably due to underestimation of the interfacial forces in the two-fluid model.
\end{abstract}

\section{Introduction}

Spillways are important hydraulic structures for dam safety. If the water flow velocity exceeds, for example, $20 \mathrm{~m} / \mathrm{s}$ and the cavitation index drops below a certain limit, damage may occur due to cavitation in the chute bottom, which affects the safety of the spillway [1]. Hence, protecting spillways from cavitation damage is a primary goal of engineering design. The use of aerators is probably the only economic countermeasure for the purpose. An aerator entrains air into high-speed flow, alleviates the negative pressure near the chute bottom, and thus avoids the risk of cavitation.

Driven by engineering practice, researchers have investigated aerators both in the laboratory and through prototype observations [2-8]. Kramer and Hager [9] examined, through experiments, flow velocity, air concentration, and air bubble size distributions; they concluded that the bubble rise velocity in chute flows depends on the Froude number. Pfister and Hager $[7,8]$ analyzed the effects of geometrical parameters on streamwise distributions of air concentration downstream of aerators.
For many years, physical models have been the major tool to study the characteristics of the aerated flow. Computational Fluid Dynamics (CFD) has emerged as an important alternative in multiphase flow modelling. Both methods are undoubtedly complementary to each other. With CFD, it is possible to obtain, in detail, air-water flow fields of the aerated flow so as to understand the effects of governing parameters necessary for a project in question.

The Volume of Fluid (VOF) method is an interface tracking scheme addressing the topological changes of the air-water interface in free-surface flows [10]. To describe its hydraulic performance, the VOF model is often used to simulate the aerated flow of a spillway [11-14].

In an air-water flow, exchange behaviors between the dispersed air phase and continuous water phase affect forces between the phases. Hence, the correct modelling of forces and turbulence is of prime importance for capturing the physics. The two-fluid model differs from the VOF model in such a way that the momentum and continuity equations are solved for each phase. Furthermore, the interaction force between phases, the drag force, the virtual mass force, and 


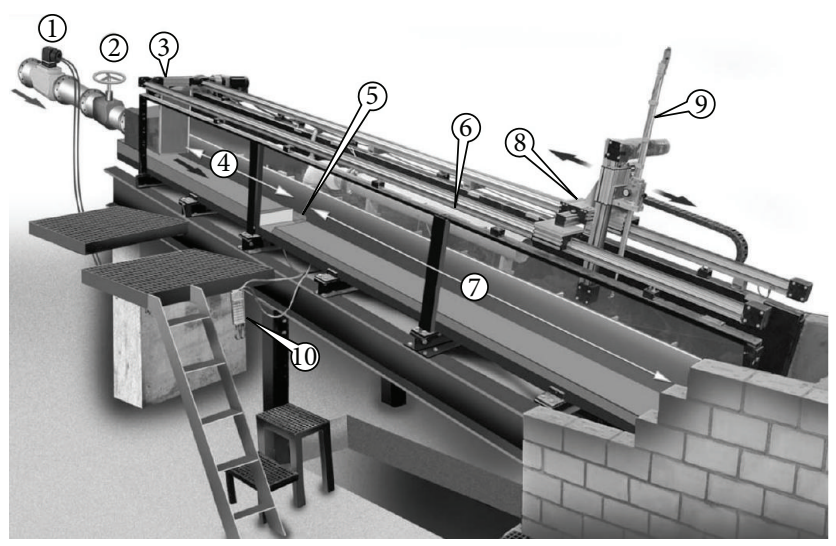

Figure 1: Chute model configuration [7] (with permission from ASCE). (1) flow meter, (2) slide valve, (3) jet-box, (4) approach flow zone, (5) aerator, (6) air duct, (7) measurement range, (8) automatic position system, (9) fiber-optical probe, and (10) cavity piezometer.

the turbulent dispersion force are modelled in the momentum equations.

The two-fluid model was used to simulate the complex hydrodynamics of air-water flow in industrial applications [15-17]. Zhang [18] carried out three-dimensional (3D) modelling with the model. He focused on evaluations of such parameters as the diameter of air bubble, wall function, and interphase exchange models. Zhang et al. [19] performed twodimensional (2D) simulations using the model, in which the turbulence dispersion force was included in the momentum equations. They concluded that the inclusion of the turbulence dispersion force gave better results of air concentration in the flow, which agreed well with the experimental data [20].

Physical model tests of an aerator were performed at the Laboratory of Hydraulics, Hydrology, and Glaciology (VAW), ETH, Zurich [7, 8]. Based on its configurations, CFD modelling is performed using the two-fluid model. The simulations, time dependent and in $2 \mathrm{D}$, examine the transport of air in the flow. Included in the study are evaluations of air cavity length, air-entrainment rate, and air concentration distributions. The effect of bubble diameter, a dominating factor in the two-fluid model, is also considered on the momentum exchange between air and water. With regard to the experimental results, the purpose of the study is to evaluate the suitability of the two-fluid model in solution of the two-phase flow at the aerator and to learn about the air-water features of the flow.

\section{Physical Model}

The experimental set of data was obtained from a hydraulic model test of an aerator conducted in a flume $0.3 \mathrm{~m}$ wide and $6.0 \mathrm{~m}$ long at VAW, ETH, Zurich (Figure 1) [7]. One aerator configuration, without offset but with a deflector, is selected for the numerical modelling (Figure 2). The chute bottom angle is set herein to $\alpha=30^{\circ}$ with the horizontal plane; the defector angle is $\varphi=8.13^{\circ}$ with the chute bottom. The chute length upstream of the aerator is $2.0 \mathrm{~m}$. The height of defector $(s)$ is $0.0133 \mathrm{~m}$. The water depth of the approach flow is $h_{0}$ $=0.084 \mathrm{~m}$. The approach flow Froude number is defined as
$F=V_{0} /\left(g h_{0}\right)^{0.5}=7.52$, where $V_{0}$ is the mean approach flow velocity and $g$ is the acceleration of gravity.

The air supply to the air cavity below the jet occurs through a lateral duct on each side of the chute; its mass flux is measured with a thermoelectric air flow anemometer. To measure the spatial distribution of air concentration (denoted as C), a dual-tip fiber-optical probe is adopted with a sampling frequency of $1 \mathrm{MHz}$. Its measurement is based on different refraction indices between the sapphire tip and the surrounding phase. If the tips are in the air phase, the light on the tips is reflected and detected. Otherwise, it is "lost" in the water phase. The $C$ value at each point is obtained from a period of typically $20 \mathrm{~s}$. The measurement points have a streamwise spacing of $0.2 \mathrm{~m}$; the interval perpendicular to the chute bottom is 2 to $5 \mathrm{~mm}$.

For the approach flow, the Weber and Reynolds number is defined as We $=V_{0} /\left(\sigma / g h_{0}\right)$ and $\operatorname{Re}=\left(V_{0} h_{0}\right) / \mu_{w}$, where $\sigma$ is the surface tension and $\mu_{w}$ is the kinematic water viscosity. If they exceed the minimum values, that is, $\mathrm{We}=110$ and $\mathrm{Re}$ $=1.7 \times 10^{5}$, the effects of surface tension and viscous force are negligible [21-25]. In the tests, $\mathrm{We}=236$ and $\mathrm{Re}=1.3 \times 10^{6}$, both exceeding the limits.

\section{Numerical Model}

A numerical model was set up to simulate the water-air flow at the aerator. The computations are based on the two-fluid model in ANASYS 15 [26-28].

3.1. Two-Fluid Model. The two-fluid model is based on the Euler-Euler approach. Both separate and interacting phases are allowed to be modelled. In the model, the continuity and momentum equations are formulated for each phase.

The continuity equation for each phase is

$$
\frac{\partial}{\partial t}\left(\alpha_{i} \rho_{i}\right)+\nabla \cdot\left(\alpha_{i} \rho_{i} \vec{v}_{i}\right)=0
$$

where subscript $i=a$ and $w$, referring to the air and water phase, $\alpha_{i}$ is the phase volume fraction, $\rho_{i}$ is the phase density, $\vec{v}_{i}$ is the phase velocity, and $t$ is the time. 


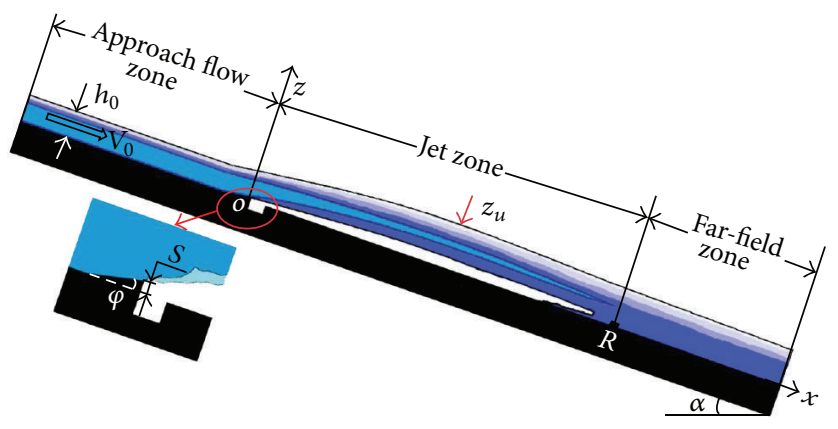

FIgURE 2: Aerator configuration.

The momentum balance equation for each phase is

$$
\begin{aligned}
& \frac{\partial}{\partial t}\left(\alpha_{i} \rho_{i} \vec{v}_{i}\right)+\nabla \cdot\left(\alpha_{i} \rho_{i} \vec{v}_{i} \vec{v}_{i}\right) \\
& =-\alpha_{i} \nabla p+\nabla \cdot \vec{\tau}_{i}+\alpha_{i} \rho_{i} g+G+M,
\end{aligned}
$$

where $p$ is the water pressure, $\tau_{i}$ is the shear stress, $G$ is the interphase force, and $M$ is the interfacial force between air and water phase.

$G$ depends on water-air friction, pressure, cohesion, and other effects and is written as a simple interaction term of the following form:

$$
G_{a w}=K_{a w}\left(\vec{v}_{a}-\vec{v}_{w}\right)
$$

where $K_{a w}=K_{w a}=$ interphase momentum exchange coefficient between the water and the air phase.

$M$ consists of several independent forces:

$$
M=M_{d, w}+M_{l, w}+M_{v m, w}+M_{t d, w},
$$

where $M_{d, w}$ is the drag force, $M_{l, w}$ is the lift force, $M_{v m, w}$ is the virtual mass force, and $M_{t d, w}$ is the turbulence dispersion force. In the two-fluid model, the air phase is assumed to form bubbles. The viscous stress creates bubble skin drag; the pressure distribution around the bubble creates form drag. The latter becomes significant when the relative bubble Reynolds number $\left(\operatorname{Re}_{r}\right)$ increases. $M_{d, w}$ is written as

$$
M_{d, w}=\frac{K_{D} \mathrm{Re}_{r}}{24}
$$

where $K_{D}$ is the drag coefficient. $\mathrm{Re}_{r}$ is obtained from

$$
\operatorname{Re}_{r}=\frac{\rho_{w}\left|\vec{v}_{a}-\vec{v}_{w}\right| D}{\mu_{w}},
$$

where $D$ is the bubble diameter. $K_{D}$ is based on the Schiller and Naumann model [29]:

$$
K_{D}= \begin{cases}\frac{24\left(1+0.15 \mathrm{Re}_{r}^{0.687}\right)}{\mathrm{Re}_{r}} & \mathrm{Re}_{r} \leq 1000 \\ 0.44 & \mathrm{Re}_{r}>1000 .\end{cases}
$$

If bubbles accelerate relative to the water, virtual mass effects occur. $M_{v m, w}$ is due to the inertia of the water mass encountered by the accelerating bubbles [30], defined as

$$
M_{v m, w}=0.5 \alpha_{a} \rho_{w}\left(\frac{d \vec{v}_{w}}{d t}-\frac{d \vec{v}_{a}}{d t}\right) .
$$

The virtual mass effect is significant when the secondaryphase density is much smaller than the primary-phase density.

$M_{t d, w}$ acts as a turbulent diffusion in dispersed flows and is based on de Bertodano [31]:

$$
M_{t d, w}=-M_{t d, a}=K_{t d} \rho_{w} k_{w} \nabla \alpha_{a}
$$

where $k_{w}$ is the water turbulent kinetic energy per unit of mass and $K_{t d}$ is the turbulence dispersion coefficient.

$M_{l, w}$ acts on air bubbles mainly due to velocity gradients in the water flow field. From Drew and Lahey [30], it is written as

$$
M_{l, w}=-K_{l} \rho_{w} \alpha_{a}\left(\vec{v}_{w}-\vec{v}_{a}\right) \times\left(\nabla \times \vec{v}_{w}\right),
$$

where $K_{l}$ is the lift coefficient.

3.2. Grid, Boundary Conditions, and Grid Independence. The chute included in the simulations comprised 2.0 and $5.06 \mathrm{~m}$ upstream and downstream of the aerator. The upper boundary of the domain is parallel to the chute bottom and at a distance of $1.2 \mathrm{~m}$ from it. The height of the transversal groove is $H=0.03 \mathrm{~m}$; the duct width is $B=0.06 \mathrm{~m}$. The bottom of the duct is open to atmosphere, allowing air to be sucked into the jet cavity.

A quadrilateral mesh is generated in the Gambit software. The geometrical size and numerical grids are shown in Figure 3. The boundary conditions are defined in Figure 4. The upstream boundary consists of both water and air in height. A velocity boundary is set to the water phase below; a pressure inlet (the atmospheric pressure) is given to the air phase above the water. Both the top and the duct bottom are specified as pressure inlet; the downstream boundary is set as pressure outlet. The other boundaries are treated as wall.

Simulations are performed in 2D and time dependently using the software Fluent in ANSYS 15. Zhang [18] compared the Standard $k-\varepsilon$ and Realizable $k-\varepsilon$ models for aerated 


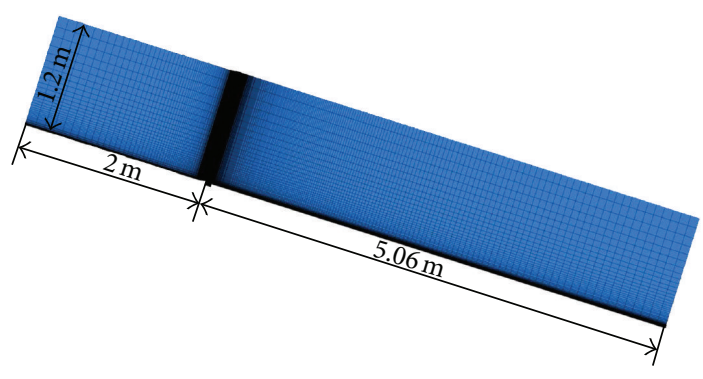

(a) Entire domain

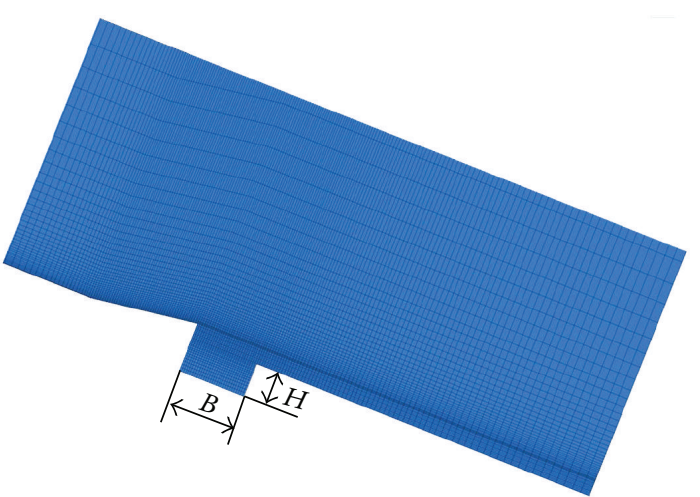

(b) Local refinement at the aerator

FIgURE 3: Numerical grid.

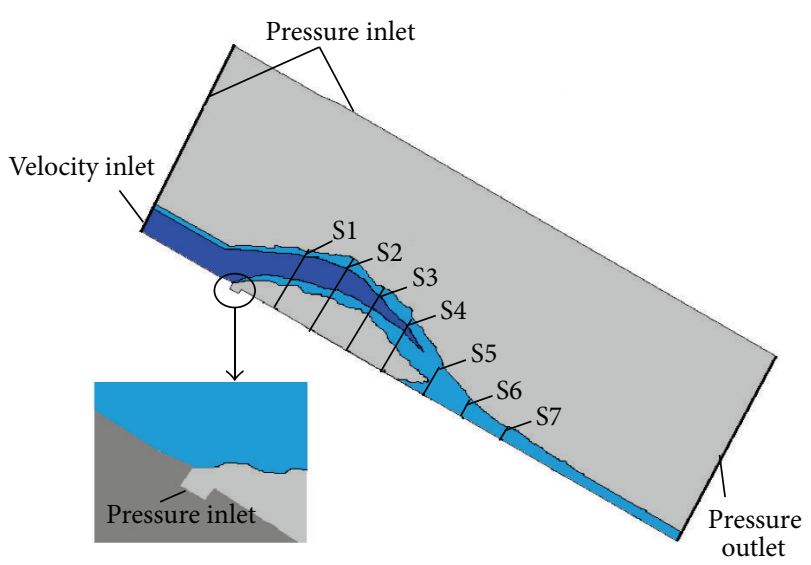

FIGURE 4: Numerical boundary conditions.

flow. The results have shown that there are small differences between them. However, the Realizable $k-\varepsilon$ model is more suitable to represent features of turbulent free-surface flow [32]. Hence, it is chosen in the simulations. The parameters chosen for use in the two-fluid model are summarized in Table 1.

To guarantee the numerical quality, a check of grid independence is necessary. Three quadrilateral grids are examined, with the number of cells being about 9900 (coarse), 33000 (medium), and 66000 (fine), respectively. The minimum cell size is $1 \mathrm{~mm}$ at the aerator. The variable $z_{u}$ refers to the position corresponding to $C=0.9$ in the upper edge of the nappe (Figure 2). For the grid independence check, the $C$ values are compared as a function of $Z=z / z_{u}$. The comparison for location $x=0.211 \mathrm{~m}$ is shown in Figure 5 . The results indicate that the medium size grid is sufficient to model the aerator flow.

\section{Results and Discussions}

The flow field is usually divided into three zones, that is, approach flow zone, air cavity zone, and far-field zone (Figure 2). The latter two zones are divided by the reattachment point $(\mathrm{R})$, defined as the intersection of $C=0.9$ with

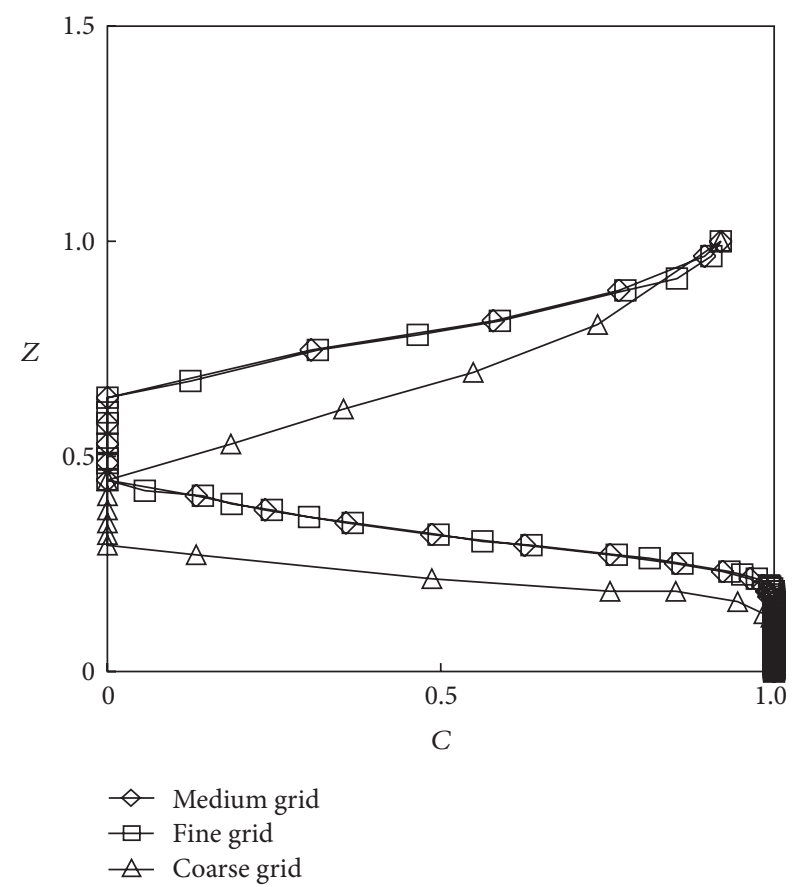

Figure 5: Check of grid independence (at location $x=0.211 \mathrm{~m}$ ).

the chute bottom. The main issues of concern for modelling, either physical or numerical, include the air demand, cavity length, and air concentration in the cavity zone, at the end of the cavity and in the far field of the jet.

A coordinate system $(x, z)$ is defined. The $x$-direction is on the chute bottom, while the $z$-direction, perpendicular to the chute bottom, is on the downstream face of the deflector (Figure 2). Several cross sections, denoted as S1-S7 and all perpendicular to the chute bottom, are used to describe the flow (Table 2). The distance between two neighboring locations is $0.2 \mathrm{~m}$.

4.1. Selection of Bubble Diameter. The air phase exists presumptively in the form of bubbles. The air-water exchange behavior is a dominating issue in modelling aerator flow 
TABLE 1: Summary of parameters in the two-fluid model.

\begin{tabular}{lcccc}
\hline Drag force model & Turbulence model & Virtual mass force model & $\begin{array}{c}\text { Turbulence dispersion } \\
\text { force model }\end{array}$ & Lift force model \\
\hline Schiller and Naumann & Realizable $k-\varepsilon$ & Drew and Lahey & de Bertodano & Drew and Lahey \\
\hline
\end{tabular}

TABLE 2: Locations of cross sections.

\begin{tabular}{|c|c|c|c|c|c|c|c|}
\hline & S1 & S2 & S3 & S4 & S5 & S6 & S7 \\
\hline$x(\mathrm{~m})$ & 0.211 & 0.411 & 0.611 & 0.811 & 1.011 & 1.211 & 1.411 \\
\hline
\end{tabular}

and is influenced by the bubble dimensions. In the two-fluid model, this behavior is described by $K_{a w}$ :

$$
K_{a w}=\frac{\rho_{a} M_{d, w}}{6 \tau_{a}} D A
$$

where $A$ is the interfacial area, $\tau_{a}=\left(\rho_{a} D^{2}\right) /\left(18 \mu_{a}\right)$, and $\mu_{a}$ is the air kinematic viscosity.

Chanson and Toombes [33] carried out an experiment in an open channel to study air-water flow properties. They indicated that the probability of air bubble chord sizes between 0 and $4 \mathrm{~mm}$ in the flow region is more than $65 \%$. Takahashi et al. [34] conducted a study of interactions between freesurface and cavity recirculation in a stepped channel. The results showed that the majority of bubble diameters is below $5 \mathrm{~mm}$. Chen et al. [35] studied bubble diameter distributions in an aerated flow by means of physical model tests. They showed that the bubble sizes are commonly in the range of $0.5-3 \mathrm{~mm}$ in the vicinity of the chute bottom and $3-5 \mathrm{~mm}$ close to the free surface.

In the VAW laboratory tests, no systematical measurements were made of the air bubble sizes. However, fragmentary tests demonstrated that they were usually below $4 \mathrm{~mm}$. With reference to the abovementioned observations, $D=1,2$, 3 , and $4 \mathrm{~mm}$ are selected to examine their effects on the flow characteristics.

4.2. Cavity Length and Air Demand. When the water flows over the aerator, then the deflector separates the flow from the bottom and a cavity region beneath the nappe of the jet is generated, in which air is sucked in. The cavity length and the air supply are two characteristic parameters of interest. Due to the high velocity and turbulence, a well-defined interface between the air and water does not exist for the lower nappe surface. The cavity length, denoted as $L(\mathrm{~m})$, refers to the distance from the aerator to the reattachment point $R$ on the chute bottom (Figure 2). To describe the air-entrainment capacity of an aerator, an air-entrainment coefficient $(\beta)$ is defined as the ratio of air discharge $\left(Q_{a}, \mathrm{~m}^{3} / \mathrm{s}\right)$ to water flow discharge $\left(Q_{w}, \mathrm{~m}^{3} / \mathrm{s}\right)$.

Other conditions being given, the bubble diameter $D$ is a primary parameter in the two-fluid model. In literature review, limited information has been found of its effects on the cavity length and the air demand. Table 3 compares the averaged results of $L$ from the experiments and the numerical simulations. The simulated $L$ values are in relatively good
TABLE 3: Comparison of $L$ 's between experiments and simulations.

\begin{tabular}{lccccc}
\hline \multicolumn{3}{c}{ Experiments } & \multicolumn{4}{c}{ Simulations } \\
& & $D=1 \mathrm{~mm}$ & $D=2 \mathrm{~mm}$ & $D=3 \mathrm{~mm}$ & $D=4 \mathrm{~mm}$ \\
\hline$L(\mathrm{~m})$ & 1.120 & 1.175 & 1.161 & 1.152 & 1.155 \\
\hline
\end{tabular}

agreement with the experimental one; the maximal difference is $5 \%$ for $D=1 \mathrm{~mm}$.

As the black-water core stretches to the end of the cavity, the air supply to the aerator is equal to the air entrained into the flow from the lower nappe surface. Table 4 shows the $\beta$ results corresponding to the different $D$ values. With the increase of $D$, the $\beta$ value becomes smaller. $D=1 \mathrm{~mm}$ gives the largest difference; $D=4 \mathrm{~mm}$ is closer to the experimental result, with an error of $9 \%$. All the simulations overestimate the air demand. $D$ is a parameter that does affect the air entrainment.

4.3. Cavity-Zone Air Concentration. Air is entrained into the water by strong emulsification in the cavity zone, particularly at its end near the reattachment zone. If the aerator geometry is given, the state of air entrainment governs the air capacity of the aerator, which forms an initial condition for the streamwise transport of the air in the water. Figure 6 shows the $C$ distributions as a function of $Z$ for the four locations S1, S2, S3, and S4 (Figure 4). Each diagram compares the distributions between the experiments and the simulations. The $D$ values vary from 1 to $4 \mathrm{~mm}$.

For the upper edge of the nappe, the four $D$ values lead to almost identical results at $\mathrm{S} 1$ and differ however from the experimental result; the range of the so-called black-water zone is underestimated. As the streamwise distance increases from the aerator, the simulated $C$ values corresponding to the larger diameters decrease and approach gradually the experimental ones. At S4, the result of $D=4 \mathrm{~mm}$ is in good agreement with the experimental data.

For the lower edge of the nappe, the numerical and test results are more close to each other along the cavity. Some small differences are seen for $D=1 \mathrm{~mm}$ in the beginning of the cavity (e.g., at $\mathrm{S} 1$ ) and $D=4 \mathrm{~mm}$ towards downstream (e.g., at S3 and S4).

4.4. Lower Edge Concentration Similarity. To further examine the air concentration of the lower nappe edge, a characteristic thickness, called the air-entrainment thickness $\delta$, is usually used to describe its development $[20,36]$. For a given cross section, it refers to the difference between $C=30 \%$ and $60 \%$; that is, $\delta=z_{30}-z_{60}$. A normalized thickness, $\eta$, is then defined as $\eta=\left(z-z_{60}\right) / \delta$. For the four locations, Figure 7 compares the changes of the $C$ values as a function of $\eta$. 
TABLE 4: Comparison of $\beta$ 's between experiments and simulations.

\begin{tabular}{lccccc}
\hline & \multirow{2}{*}{ Experiments } & \multicolumn{2}{c}{ Simulations } \\
& & $D=1 \mathrm{~mm}$ & $D=2 \mathrm{~mm}$ & $D=3 \mathrm{~mm}$ & 0.0460 \\
$Q_{a}\left(\mathrm{~m}^{3} / \mathrm{s}\right)$ & 0.0393 & 0.0629 & 0.0550 & 0.0430 \\
$\beta$ & 0.228 & 0.365 & 0.319 & 0.267 & 0.249 \\
\hline
\end{tabular}

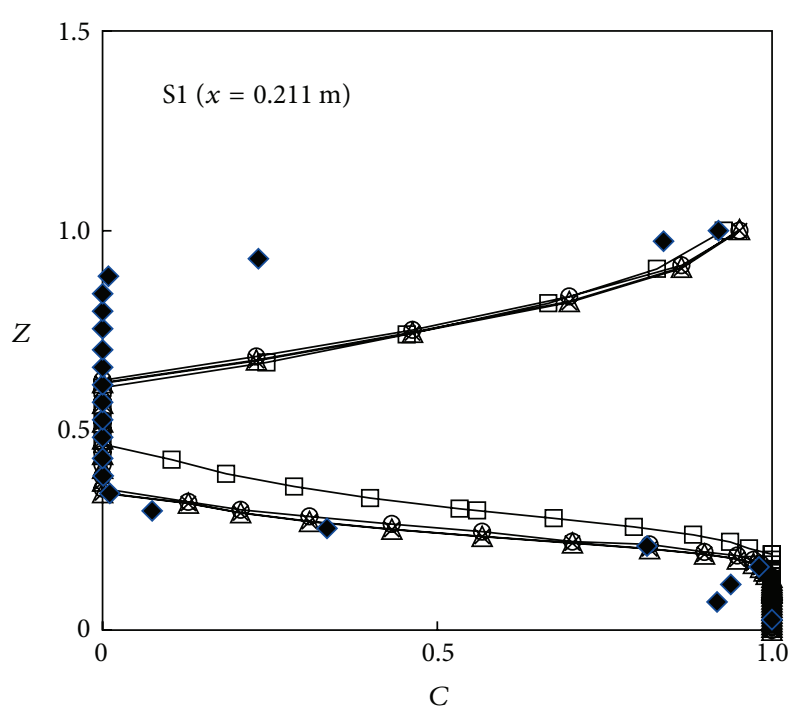

- Experiments

$\square D=1 \mathrm{~mm}$ $\triangle D=2 \mathrm{~mm}$

(a) Cross section $\mathrm{S} 1$

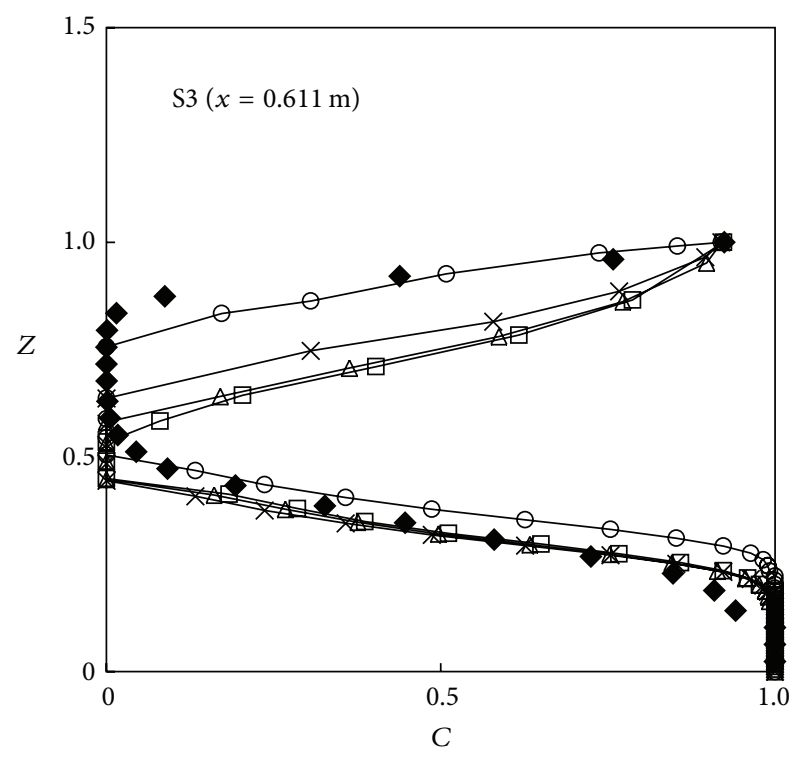

- Experiments

$\square D=1 \mathrm{~mm}$

$\star D=3 \mathrm{~mm}$

$\triangle D=2 \mathrm{~mm}$

(c) Cross section $\mathrm{S} 3$

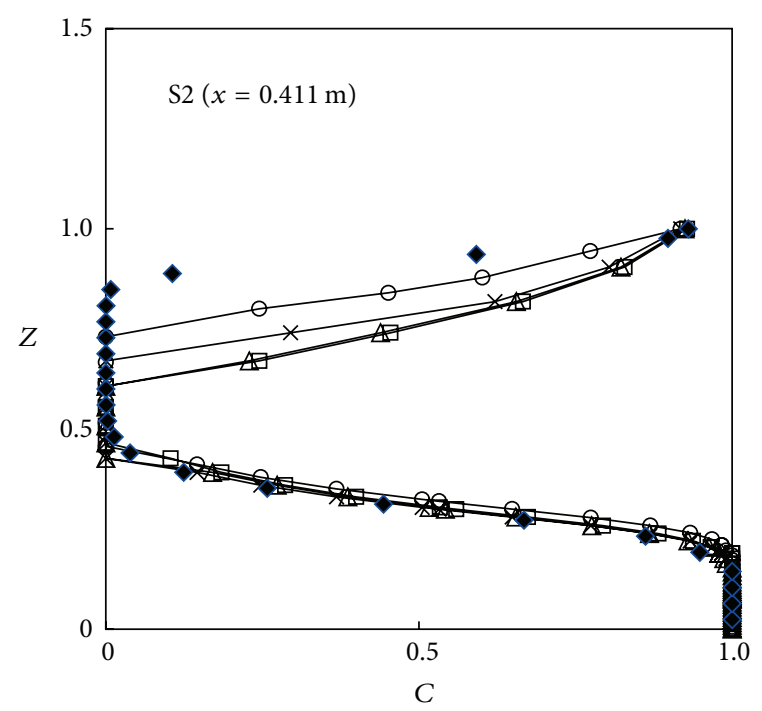

$\begin{array}{ll}- \text { Experiments } & * D=3 \mathrm{~mm} \\ \square D=1 \mathrm{~mm} & -D=4 \mathrm{~mm}\end{array}$

$\triangle D=2 \mathrm{~mm}$

(b) Cross section $\mathrm{S} 2$

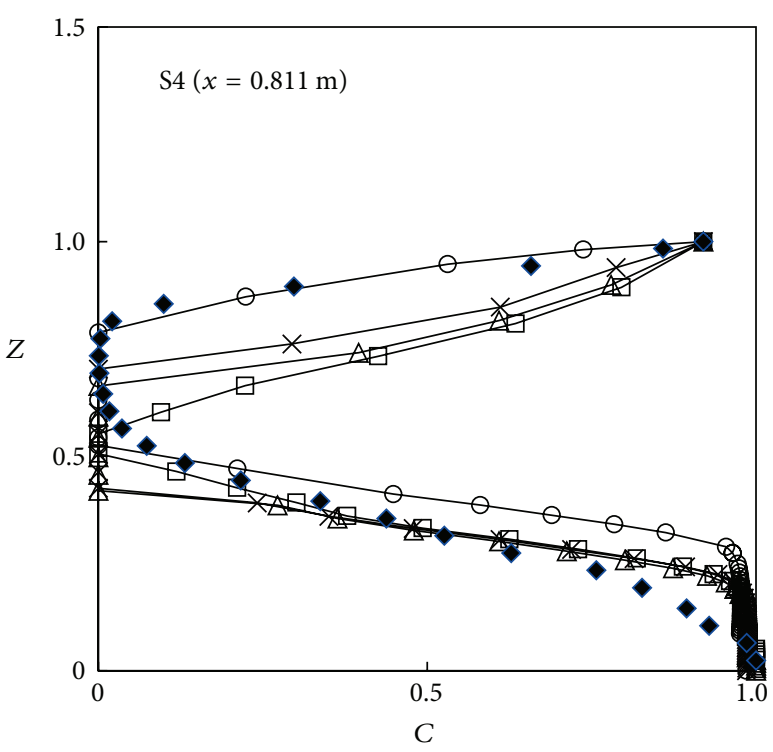

- Experiments $\quad * D=3 \mathrm{~mm}$

$\square D=1 \mathrm{~mm} \quad \multimap D=4 \mathrm{~mm}$

$\triangle D=2 \mathrm{~mm}$

(d) Cross section $\mathrm{S} 4$

Figure 6: $C$ distributions. 


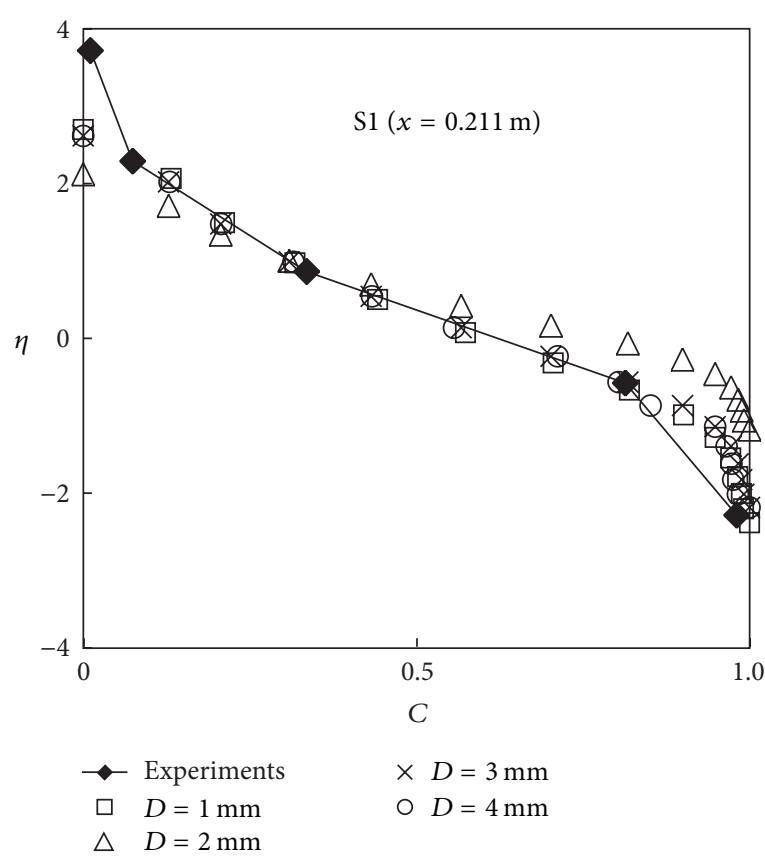

(a) Cross section $\mathrm{S} 1$

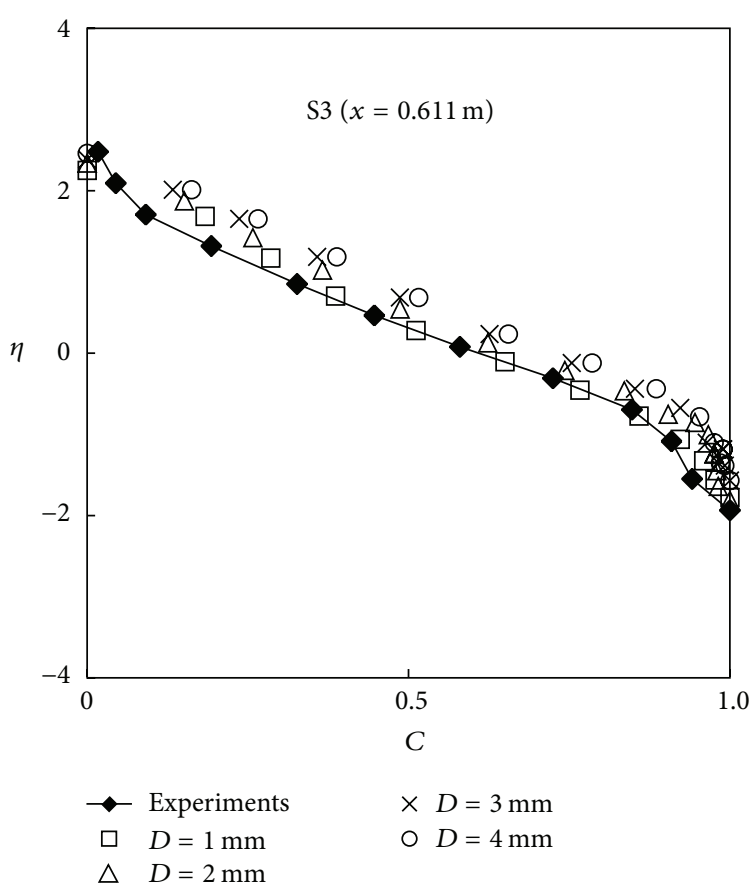

(c) Cross section $\mathrm{S} 3$

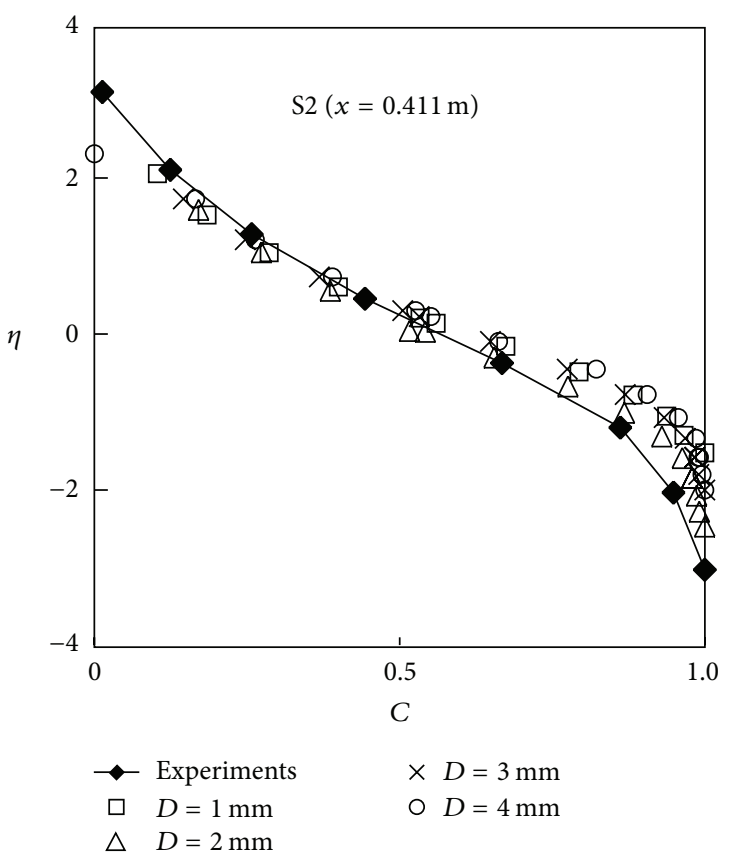

(b) Cross section $\mathrm{S} 2$

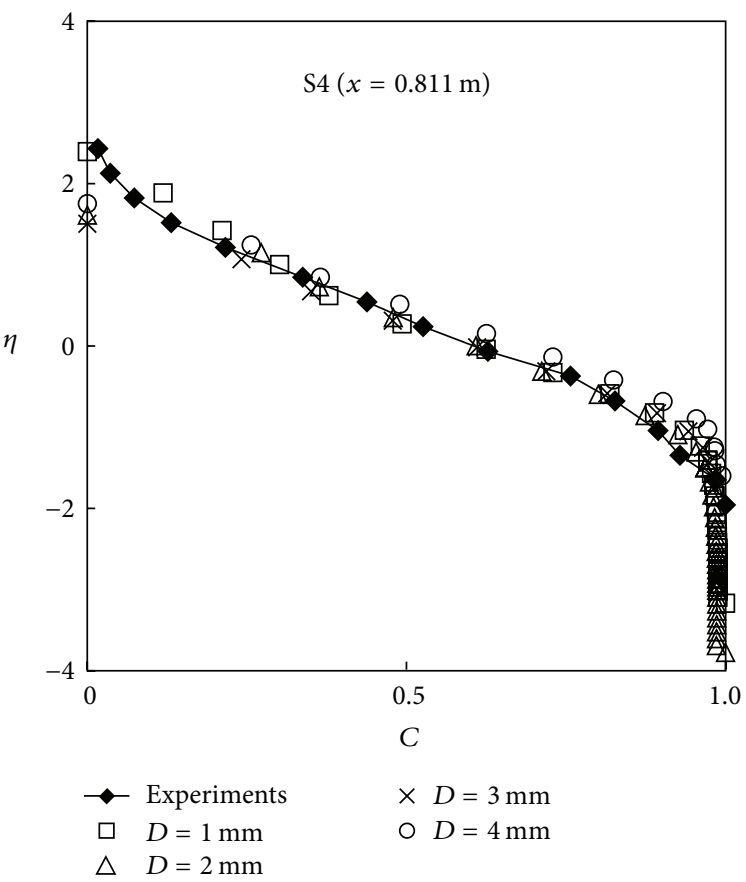

(d) Cross section $\mathrm{S} 4$

Figure 7: Similarity of $C$ distributions.

Figure 8 is a plot of all the experimental $C$ values for the lower edge. The $C$ distributions are similar for different locations and can be assembled into the expression suggested by Hager [37]:

$$
C(\eta)=m_{1} \exp \left(-m_{2}\left(\eta+m_{3}\right)^{2}\right),
$$

where $m_{1}, m_{2}$, and $m_{3}$ are constants, $m_{1}=1.04, m_{2}=0.16$, and $m_{3}=1.87$.
4.5. Cavity End. The air content at end of the cavity evolves from the air entrainment along the lower edge of the jet; at the same time, it reflects also the air contribution from the backflow upstream of the reattachment point $R$ and its interaction with the jet's lower edge.

Section S5 is located at the end of the cavity. Figure 9 compares, along the whole cross section, the $C$ distributions between the experiments and the modelling. Figure 10 shows 


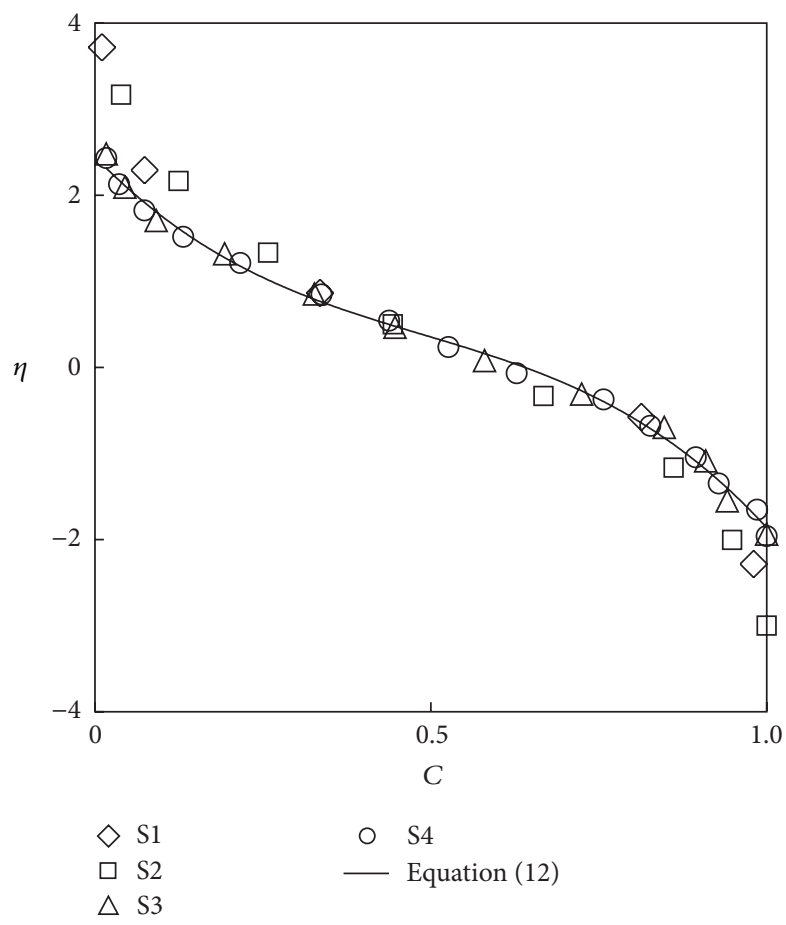

FIGURE 8: Similarity of $C$ distributions for experiments.

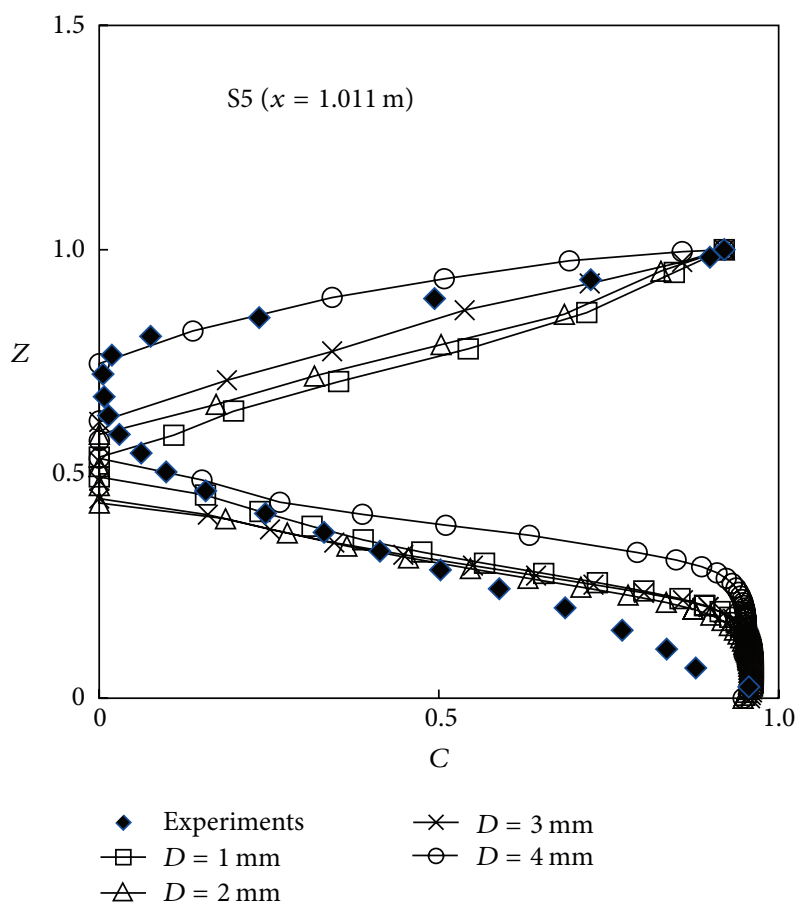

Figure 9: $C$ distribution at S5.

the similarity profile of $C$, that is, the change of $C$ as a function of $\eta$.

From the experiments, one can see that the blackwater zone becomes small at S5 and is about to disappear downstream of it. The thickness of the black water is relatively well produced; its predicted position is however lower. Again,

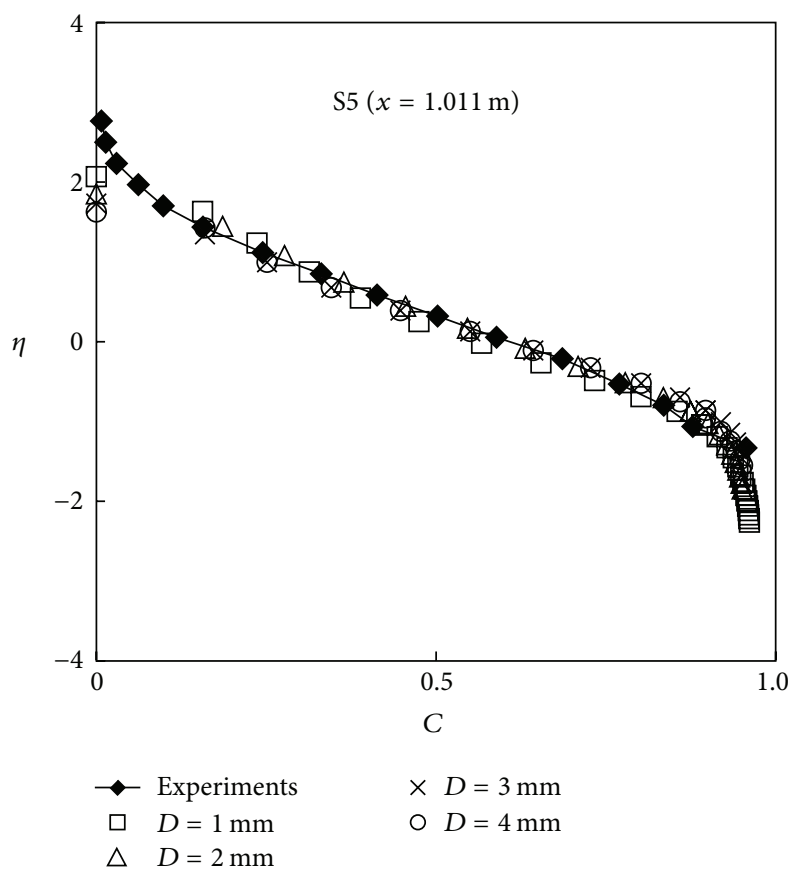

FIgURE 10: Similarity of $C$ distribution at S5.

the high air concentration region close to the chute bottom edge is overestimated in the simulations.

4.6. Far-Field Evolution. It is the aerated air bubbles close to the bottom that protect the chute bottom from cavitation damage. It is therefore of practical significance to examine the streamwise development downstream of the reattachment point $R$. It provides information with respect to the effective length of the chute provided by the aerator in question.

Figure 11 shows the $C$ profiles at two typical cross sections (S6 and S7) in the far filed, that is, the change of $C$ with $Z$. The $C$ distributions behave in a similar manner for the examined $D$ range. For both the upper edge and lower boundary of the flow, $C$ is overestimated; all the simulations lead to a much larger $C$ value close to the chute bottom. The average $C$ value at each location is well reproduced.

4.7. Discussions. As seen from (11), $D$ is a parameter that affects the diffusion between the air and water; the momentum exchange becomes more intense with augment in $D$. In the simulations, $D$ is a constant value in the entire computational domain. In actual situations, it may vary in the different flow regions. In the approach flow, with the increase of the surface turbulence, air starts to be entrained from the free surface at a location upstream of the aerator. Compared with the flow in the cavity zone, the turbulence intensity in the flow is low [6]. As a result, the $C$ distribution of the approach flow might still be overestimated even with the smallest diameter simulated $(D=1 \mathrm{~mm})$.

Previous model tests showed that the roughness of the surface water increases along the cavity zone [9]. This implies that the exchange of momentum between the water and air becomes stronger; a larger bubble diameter should be used to 


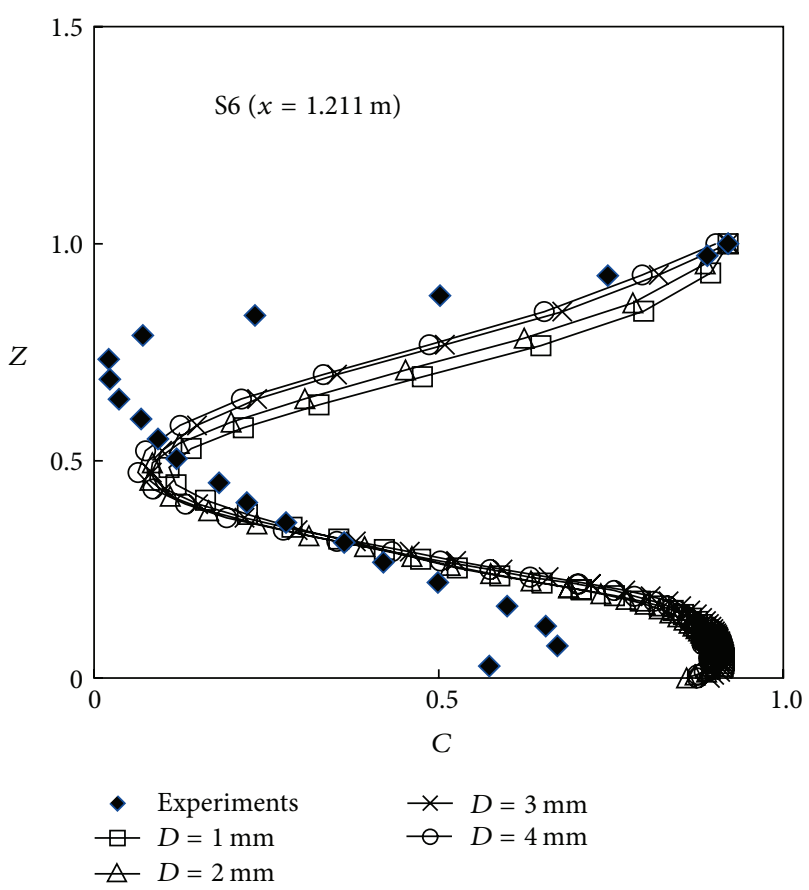

(a) Cross section $\mathrm{S} 6$

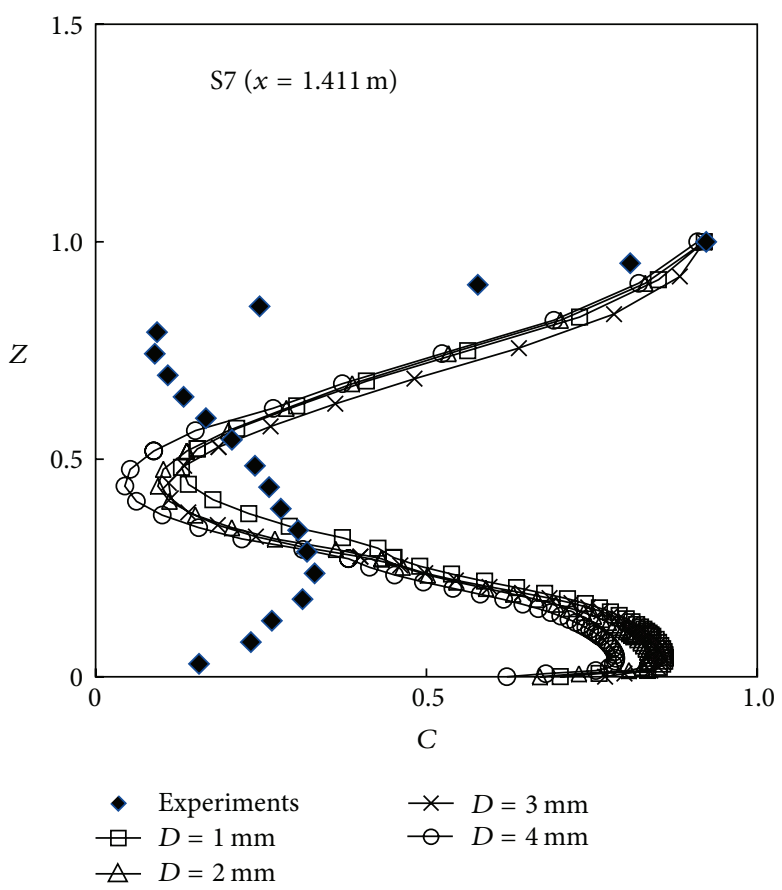

(b) Cross section S7

FIGURE 11: $C$ distribution at $S 6$ and S7.

describe the process. This is the reason why good agreement is obtained for the upper edge with $D=4 \mathrm{~mm}$. For the lower trajectory, the simulations show only small deviations from the experiments. The turbulence intensity is high, but not as high as that for the upper edge. The result is somewhat insensitive to $D$, but smaller $D$ values than $4 \mathrm{~mm}$ give better results for the majority part of the cavity.

In the far-field zone, the $C$ values near the chute bottom are overestimated in the simulations. Kramer and Hager [9] studied the air transport process in chute flows. They pointed out that air detrained after the reattachment point $R$ and the interfacial force between bubbles and water dominated the process of detrainment in the zone. This implies that the effects of the interfacial forces are underestimated in the twofluid model.

\section{Conclusions}

To model the air-water flow at an aerator is a challenging issue, especially if the water flow velocity is high, which is the case in most spillway installations. Based on the experimental data of ETH, Zurich, numerical simulations are performed to reproduce the characteristics of the aerated flow. The CFD model is the two-fluid model in ANSYS 15; the parameters of interest include air concentration, cavity length, and airentrainment rate. The bubble diameter affects the momentum exchange between the water and air and a range between 1 and $4 \mathrm{~mm}$ is investigated.

In terms of the cavity length, the experiments and CFD give similar results irrespective of the bubble size. The bubble diameter affects the amount of air entrained into the flow; the air flow rate from the $4 \mathrm{~mm}$ simulations is close to the measured one. Along the cavity zone, the surfacewater roughness increases; a somewhat larger bubble size is suitable to describe the exchange between the two phases. For the lower jet trajectory, the simulated air concentration is relatively nonsensitive to the bubble size. However, sizes smaller than $4 \mathrm{~mm}$ lead to results closer to the experiments. The air concentration in the far field is overestimated; the experiments showed lower air contents. The contributing reason is presumably the underestimation of the interfacial forces in the two-fluid model. Besides, the use of a single bubble diameter is not sufficient to represent the complex water-air exchange in the aerator flow but seems to be adequate as a first step.

\section{Notations}

A: Interfacial area $\left(\mathrm{m}^{2}\right)$

$a_{i}: \quad$ Constants (-)

B: $\quad$ Groove width (m)

$C$ : $\quad$ Local air concentration (-)

$D:$ Bubble diameter ( $\mathrm{mm})$

$F$ : $\quad$ Froude number (-)

$G$ : Interphase force $(\mathrm{N})$

g: Acceleration of gravity $\left(\mathrm{m} / \mathrm{s}^{2}\right)$

$H:$ Groove depth (m)

$h_{0}$ : Depth of approach flow $(\mathrm{m})$

$K_{a w}$ : Interphase momentum exchange coefficient (-)

$K_{D}$ : Drag coefficient (-) 


\begin{tabular}{|c|c|}
\hline$K_{t d}:$ & $\begin{array}{l}\text { Turbulence dispersion coefficient } \\
(-)\end{array}$ \\
\hline$K_{l}:$ & Lift coefficient $(-)$ \\
\hline$k_{w}:$ & Water turbulent kinetic energy (-) \\
\hline$L:$ & Cavity length (m) \\
\hline M: & Interfacial force $(\mathrm{N})$ \\
\hline$M_{d, w}:$ & Drag force $(\mathrm{N})$ \\
\hline$M_{l, w}:$ & Lift force $(\mathrm{N})$ \\
\hline$M_{t d, w}:$ & Turbulence dispersion force $(\mathrm{N})$ \\
\hline$M_{v m, w}:$ & Virtual mass force $(\mathrm{N})$ \\
\hline$m_{1}, m_{2}$, and $m_{3}:$ & Constants $(-)$ \\
\hline$p:$ & Water pressure $\left(\mathrm{N} / \mathrm{m}^{2}\right)$ \\
\hline$Q_{a}:$ & Air discharge $\left(\mathrm{m}^{3} / \mathrm{s}\right)$ \\
\hline$Q_{w}:$ & Water discharge $\left(\mathrm{m}^{3} / \mathrm{s}\right)$ \\
\hline Re: & Reynolds number $(-)$ \\
\hline $\operatorname{Re}_{r}:$ & Relative Reynolds number (-) \\
\hline$s:$ & Deflector height (m) \\
\hline$t:$ & Time $(s)$ \\
\hline$V_{0}:$ & Approach flow velocity $(\mathrm{m} / \mathrm{s})$ \\
\hline$\vec{v}_{i}:$ & Velocity of phase $i(\mathrm{~m} / \mathrm{s})$ \\
\hline$\vec{v}_{a}:$ & Velocity of air bubble $(\mathrm{m} / \mathrm{s})$ \\
\hline$\vec{v}_{w}:$ & Velocity of water (m/s) \\
\hline We: & Weber number $(-)$ \\
\hline$x:$ & $x$-coordinate $(\mathrm{m})$ \\
\hline$Z:$ & Normalized $z$-coordinate $(-)$ \\
\hline$z:$ & $z$-coordinate $(\mathrm{m})$ \\
\hline$z_{30}:$ & $z(\mathrm{~m})$ at $C=30 \%$ \\
\hline$z_{60}:$ & $z(\mathrm{~m})$ at $C=60 \%$ \\
\hline$\alpha:$ & Chute bottom angle $\left({ }^{\circ}\right)$ \\
\hline$\beta:$ & Air-entrainment coefficient (-) \\
\hline$\varphi:$ & Deflector angle $\left(^{\circ}\right)$ \\
\hline$\sigma:$ & Surface tension $(\mathrm{N} / \mathrm{m})$ \\
\hline$\alpha_{i}:$ & Volume fraction of phase $i(-)$ \\
\hline$\alpha_{a}:$ & Air volume fraction $(-)$ \\
\hline$\rho_{i}:$ & Density of phase $i\left(\mathrm{~kg} / \mathrm{m}^{3}\right)$ \\
\hline$\rho_{w}:$ & Water density $\left(\mathrm{kg} / \mathrm{m}^{3}\right)$ \\
\hline$\rho_{a}:$ & Air density $\left(\mathrm{kg} / \mathrm{m}^{3}\right)$ \\
\hline$\mu_{w}:$ & Kinematic water viscosity $\left(\mathrm{m}^{2} / \mathrm{s}\right)$ \\
\hline$\mu_{a}:$ & Kinematic air viscosity $\left(\mathrm{m}^{2} / \mathrm{s}\right)$ \\
\hline$\tau_{i}:$ & Shear stress of phase $i(\mathrm{~Pa})$ \\
\hline$\delta:$ & Air-entrainment thickness (m) \\
\hline$\eta:$ & $\begin{array}{l}\text { Normalized air-entrainment } \\
\text { thickness }(-) \text {. }\end{array}$ \\
\hline
\end{tabular}

\section{Competing Interests}

No potential conflict of interests was reported by the authors.

\section{Acknowledgments}

The numerical modelling presented here was carried out as part of a Ph.D. Project "Hydraulic Design of Chute Spillway Aerators," funded by Swedish Hydropower Centre (SVC). SVC has been established by the Swedish Energy Agency, Energiforsk, and Swedish National Grid together with Luleå University of Technology (LTU), Royal Institute of Technology (KTH), Chalmers University of Technology
(CTH), and Uppsala University (UU) (http://www.svc.nu). The authors are indebted to Ms. Sara Sandberg of SVC for project coordinations.

\section{References}

[1] H. Falvey, Cavitation in Chutes and Spillways, Engineering Monograph 42, United States Department of the Interior, Bureau of Reclamation, Denver, Colo, USA, 1990.

[2] P. Volkart and P. Rutschmann, "Rapid flow in spillway chutes with and without deflectors a model-prototype comparison," in Proceedings of the Symposium on Scale Effects in Modelling Hydraulic Research, Esslingen am Neckar, Germany, 1984.

[3] H. Chanson, "Flow downstream of an aerator-aerator spacing," Journal of Hydraulic Research, vol. 27, no. 4, pp. 519-536, 1989.

[4] P. Rutschmann and W. H. Hager, "Air entrainment by spillway aerators," Journal of Hydraulic Engineering, vol. 116, no. 6, pp. 765-782, 1990.

[5] M. A. Kökpinar, Air-entrainment in high speed free surface flows [Ph.D. dissertation], Department of Civil Engineering, Middle East Technical University, Ankara, Turkey, 1996.

[6] K. Kramer, Development of aerated chute flow [Ph.D. dissertation], VAW, ETH Zurich, Zurich, Switzerland, 2004.

[7] M. Pfister and W. H. Hager, "Chute aerators. I: air transport characteristics," Journal of Hydraulic Engineering, vol. 136, no. 6, pp. 352-359, 2010.

[8] M. Pfister and W. H. Hager, "Chute Aerators. II: hydraulic design," Journal of Hydraulic Engineering, vol. 136, no. 6, pp. 360-367, 2010.

[9] K. Kramer and W. H. Hager, "Air transport in chute flows," International Journal of Multiphase Flow, vol. 31, no. 10-11, pp. 1181-1197, 2005.

[10] C. W. Hirt and B. D. Nichols, "Volume of fluid (VOF) method for the dynamics of free boundaries," Journal of Computational Physics, vol. 39, no. 1, pp. 201-225, 1981.

[11] D. K. H. Ho, K. M. Boyes, and S. M. Donohoo, "Investigation of spillway behavior under increased maximum flood by computational fluid dynamics technique," in Proceedings of the Conference on the 14th Australasian Fluid Mechanics, pp. 577580, Adelaide University, Adelaide, Australia, December 2001.

[12] M. C. Aydin and M. Ozturk, "Verification and validation of a computational fluid dynamics (CFD) model for air entrainment at spillway aerators," Canadian Journal of Civil Engineering, vol. 36, no. 5, pp. 826-836, 2009.

[13] J.-M. Zhang, J.-G. Chen, W.-L. Xu, Y.-R. Wang, and G.-J. $\mathrm{Li}$, "Three-dimensional numerical simulation of aerated flows downstream sudden fall aerator expansion-in a tunnel," Journal of Hydrodynamics, vol. 23, no. 1, pp. 71-80, 2011.

[14] V. Jothiprakash, V. V. Bhosekar, and P. B. Deolalikar, "Flow characteristics of orifice spillway aerator: numerical model studies," ISH Journal of Hydraulic Engineering, vol. 21, no. 2, pp. 216-230, 2015.

[15] R. F. Mudde and O. Simonin, "Two- and three-dimensional simulations of a bubble plume using a two-fluid model," Chemical Engineering Science, vol. 54, no. 21, pp. 5061-5069, 1999.

[16] S. M. Monahan, V. S. Vitankar, and R. O. Fox, "CFD predictions for flow-regime transitions in bubble columns," AIChE Journal, vol. 51, no. 7, pp. 1897-1923, 2005. 
[17] D. Zhang, N. G. Deen, and J. A. M. Kuipers, "Numerical simulation of the dynamic flow behavior in a bubble column: a study of closures for turbulence and interface forces," Chemical Engineering Science, vol. 61, no. 23, pp. 7593-7608, 2006.

[18] X. D. Zhang, Three dimensional numerical simulation of high velocity flow in spillway tunnels [Ph.D. thesis], China Institute of Water Resources and Hydropower, Beijing, China, 2004.

[19] H.-W. Zhang, Z.-P. Liu, D. Zhang, and Y.-H. Wu, "Numerical simulation of aerated high velocity flow downstream of an aerator," Journal of Hydraulic Engineering, vol. 39, no. 12, pp. 1302-1308, 2008.

[20] Q. S. Shi, High-Velocity Aerated Flow, China Water and Power Press, Beijing, China, 2007.

[21] W. H. C. Maxwell and J. R. Weggel, "Surface tension in Froude models-correction," Journal of the Hydraulics Division ASCE, vol. 96, p. 845, 1970.

[22] P. Novak and J. Cabelka, Models in Hydraulic Engineering, Pitman, Boston, Mass, USA, 1981.

[23] J. Peakall and J. Warburton, "Surface tension in small hydraulic river models-the significance of the Weber number," Journal of Hydrology New Zealand, vol. 35, no. 2, pp. 199-212, 1996.

[24] P. Novak, A. I. B. Moffat, C. Nalluri, and R. Narayanan, Hydraulic Structures, E \& FN Spon, London, UK, 1997.

[25] V. Heller, "Scale effects in physical hydraulic engineering models," Journal of Hydraulic Research, vol. 49, no. 3, pp. 293-306, 2011.

[26] J. B. Joshi, "Computational flow modelling and design of bubble column reactors," Chemical Engineering Science, vol. 56, no. 2122, pp. 5893-5933, 2001.

[27] A. Sokolichin, G. Eigenberger, and A. Lapin, "Simulation of buoyancy driven bubbly flow: established simplifications and open questions," AIChE Journal, vol. 50, no. 1, pp. 24-45, 2004.

[28] K. Ekambara, M. T. Dhotre, and J. B. Joshi, "CFD simulations of bubble column reactors: 1D, 2D and 3D approach," Chemical Engineering Science, vol. 60, no. 23, pp. 6733-6746, 2005.

[29] L. Schiller and Z. Z. Naumann, "A drag coefficient correlation," Vdi Zeitung, vol. 77, pp. 318-320, 1935.

[30] D. A. Drew and R. T. Lahey, Particulate Two-Phase Flow, Butterworth-Heinemann, Boston, Mass, USA, 1993.

[31] M. A. L. de Bertodano, Turbulent bubbly flow in a triangular duct [Ph.D. dissertation], Rensselaer Polytechnic Institute, Troy, NY, USA, 1991.

[32] Fluent Inc, Fluent Version 6.2 User's Guide, Fluent, Lebanon, Pa, USA, 2006.

[33] H. Chanson and L. Toombes, "Strong interactions between free-surface aeration and turbulence in an open channel flow," Experimental Thermal and Fluid Science, vol. 27, no. 5, pp. 525535, 2003.

[34] M. Takahashi, C. A. Gonzalez, and H. Chanson, "Self-aeration and turbulence in a stepped channel: influence of cavity surface roughness," International Journal of Multiphase Flow, vol. 32, no. 12, pp. 1370-1385, 2006.

[35] X. P. Chen, R. Z. Xi, D. C. Shao, and B. Liang, "New concept of air entrainment effect on mitigating cavitation damage," Journal of Hydraulic Engineering, vol. 34, no. 8, pp. 70-74, 2003.

[36] M. S. Yuan, "Calculation of 2-D air concentration distribution downstream of an aerator," Journal of Hydraulic Engineering, vol. 22, no. 12, pp. 9-16, 1991.

[37] W. H. Hager, "Uniform aerated chute flow," Journal of Hydraulic Engineering, vol. 117, no. 4, pp. 528-533, 1991. 


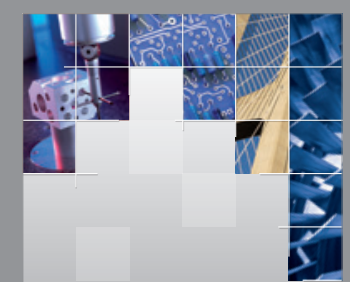

\section{Enfincering}
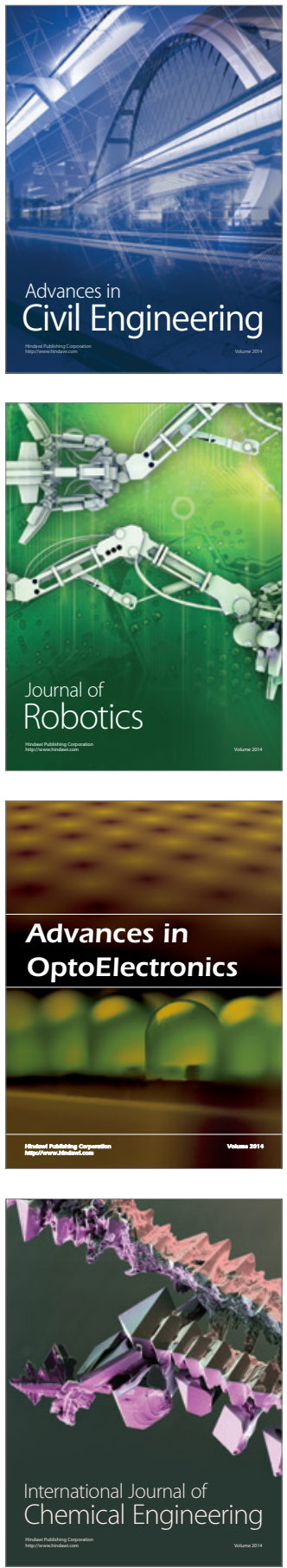

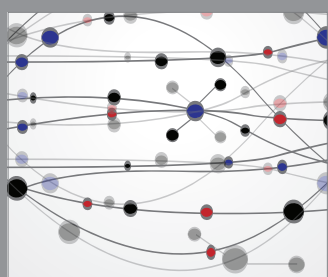

The Scientific World Journal

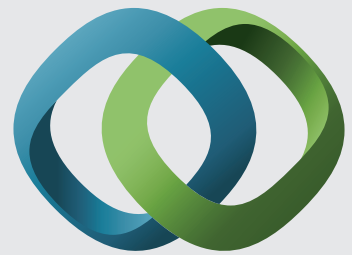

\section{Hindawi}

Submit your manuscripts at

http://www.hindawi.com
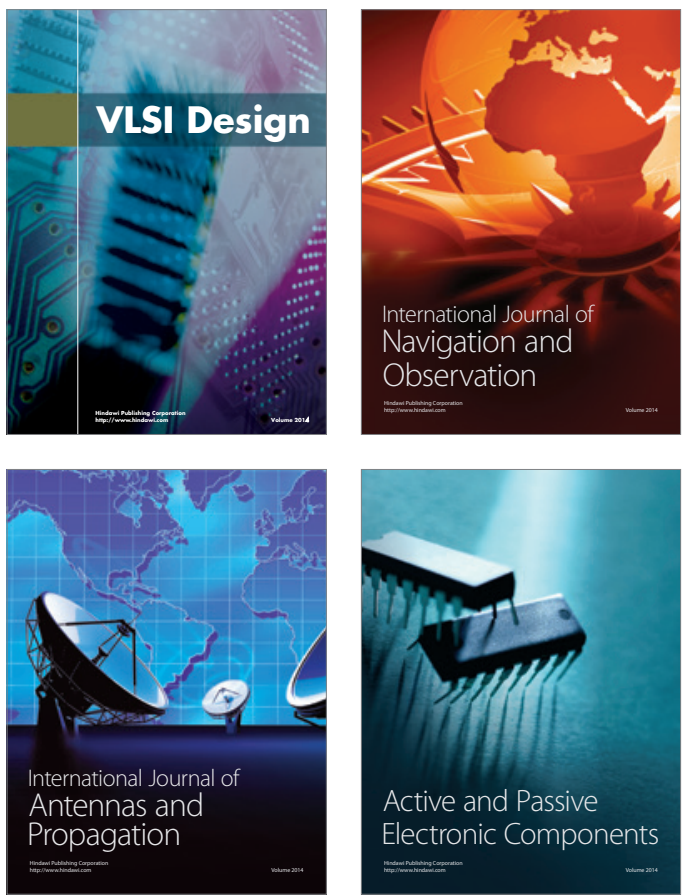
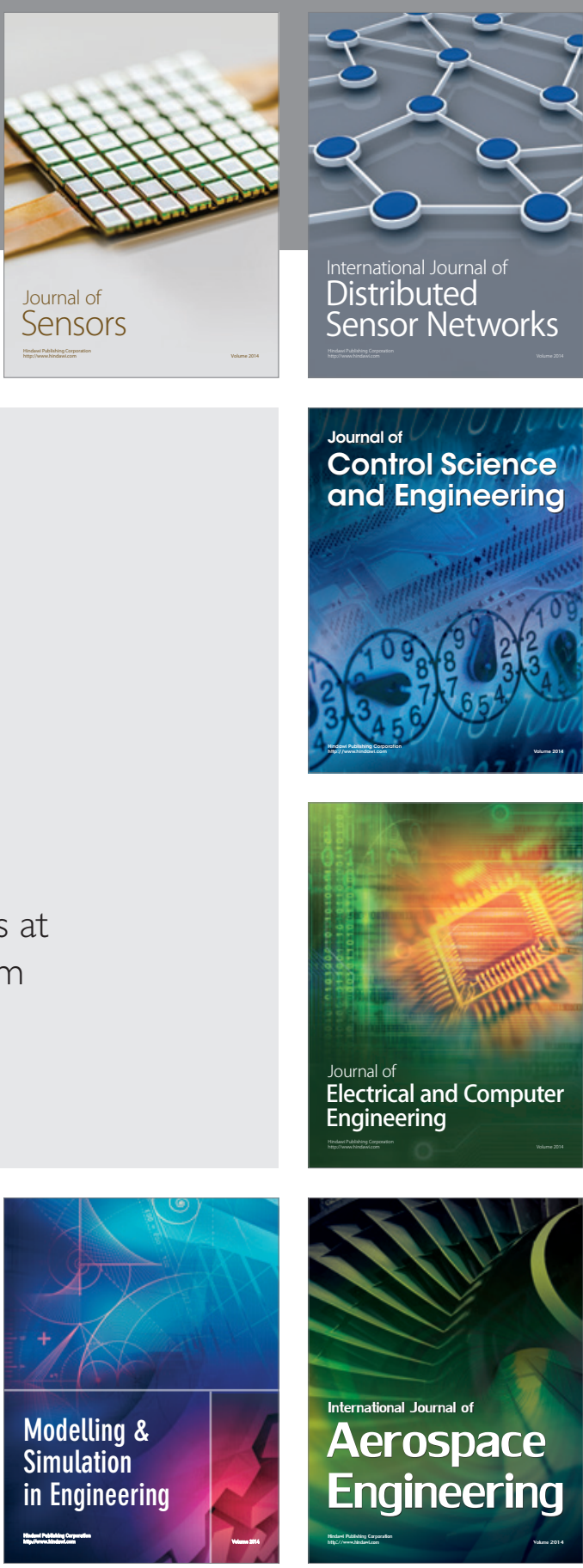

International Journal of

Distributed

Sensor Networks

Journal of

Control Science

and Engineering
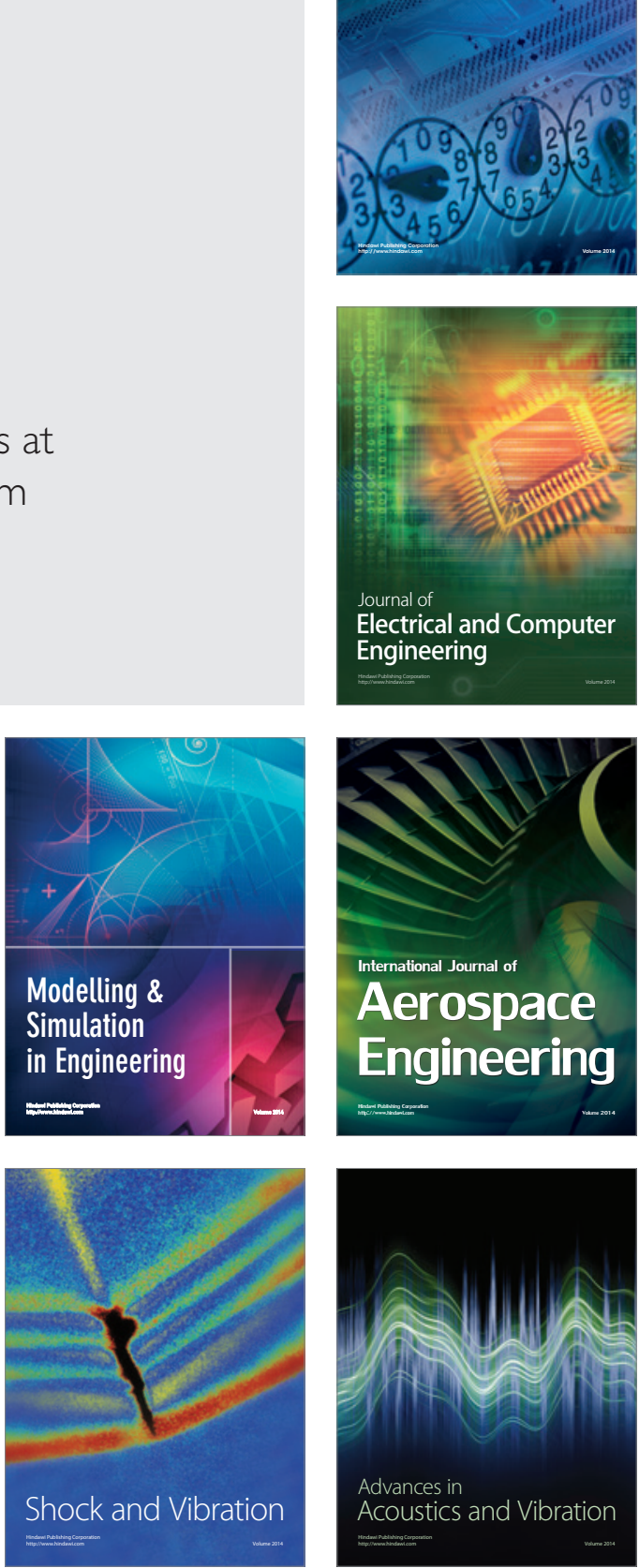